\title{
Solid-state polymerization of conjugated hexayne derivatives with different end groups
}

\author{
Satoshi Inayama, Yoko Tatewaki and Shuji Okada
}

Three hexayne derivatives with different end groups-that is, 10,12,14,16,18,20-triacontahexayne-1,30-diol (1) and its diphenylurethane (2) and diphenylester (3)-were synthesized, and their solid-state polymerization behaviors were investigated. All three monomers were thermally polymerizable. Polymers from 1 and 2 showed an absorption maximum at about $730 \mathrm{~nm}$, indicating that linear polydiacetylenes (PDAs) with octatetraynyl substituents were synthesized. However, broad absorption bands in the near-infrared region were only observed for 2 at 980 and $860 \mathrm{~nm}$, indicating that regular polymerization occurred in 2 to give ladder-type PDA. On the other hand, a polymer from 3 showed a visible absorption increase but no clear absorption maximum. It was estimated that intermolecular hydrogen bonding between hexayne monomers helps to form polymerizable stacks in 1 and 2 . In particular, urethane groups are more effective, and 2 showed the highest reactivity in this study with an ordered interlayer structure even after a two-step solid-state polymerization to give ladder-type PDA. Polymer Journal (2010) 42, 201-207; doi:10.1038/pj.2009.326; published online 23 December 2009

Keywords: ladder polymer; polydiacetylene; solid-state polymerization; $\pi$-conjugated polymer

Some butadiyne compounds are polymerized in the solid state by ultraviolet irradiation or by thermal treatment. This solid-state polymerization was clarified by Wegner $^{1}$ as a single-crystal-to-singlecrystal topochemical transition to yield polydiacetylene (PDA), which is classified as a one-dimensional $\pi$-conjugated polymer. Since the reaction is topochemically controlled, the reactivity of butadiyne monomers is greatly affected by their packing in crystals. ${ }^{2}$ In fact, when the butadiyne monomers in crystals have a stacking distance $d$ of about $5 \AA$ between adjacent molecules in the array and an angle $\theta$ of about $45^{\circ}$ between the butadiyne rod and stacking axis, 1,4addition polymerization occurs. Since molecular packing in crystals is determined by the intermolecular interactions between monomers, the selection of substituents attached to the butadiyne moiety is quite important in the preparation of PDAs. On the other hand, much research on the physical properties of PDAs, such as electrical, ${ }^{3,4}$ chromic $^{5-7}$ and nonlinear optical (NLO) $)^{8-10}$ properties, which originate from the $\pi$-conjugated backbone structure, have been undertaken. In particular, the third-order NLO properties of PDAs have attracted interest. To achieve larger NLO susceptibility $\left(\chi^{(3)}\right)$ in PDA, it is necessary to increase the density of the $\pi$-conjugated polymer backbone and the $\pi$-electron number in a repeating unit. In this connection, we have synthesized ladder-type PDAs, in which two polymer backbones were introduced in a repeating unit. ${ }^{11,12}$ In addition, several PDAs with $\pi$-conjugated substituents, such as aromatic rings and $\mathrm{C}-\mathrm{C}$ multiple bonds, directly bound to the polymer backbone $e^{13-22}$ have been synthesized to obtain PDAs with absorption maxima at longer wavelengths, resulting in larger $\chi^{(3)}$-values. In particular, oligoyne derivatives with five or more conjugated acetylenes yielded ladder polymers with $\pi$-conjugation between two PDA backbones, as shown in Figure $1 .^{20-22}$ At first, one of the butadiyne groups in the oligoyne moiety is polymerized to yield a linear PDA structure (reaction I); thereafter, the other side of the butadiyne group is polymerized to produce the ladder-type PDA structure (reaction II). The interesting electron spin behavior caused by this peculiar $\pi$ conjugation system has been reported. ${ }^{23}$ Recently, these ladder-type conjugated structures have been theoretically investigated as low bandgap materials with unusual electronic and optical properties. ${ }^{24}$

The hexayne compounds prepared in previous studies belong to alkyl $\left(-\left(\mathrm{CH}_{2}\right)_{13}-\mathrm{CH}_{3}\right)^{20}$ or alkylurethane $\left(-\left(\mathrm{CH}_{2}\right)_{5}-\mathrm{O}-\mathrm{CO}-\mathrm{NH}-\mathrm{CH}_{2}-\right.$ $\left.\mathrm{CO}-\mathrm{O}-\left(\mathrm{CH}_{2}\right)_{3}-\mathrm{CH}_{3}\right)^{21}$ groups. Alkyl-substituted hexayne has a high solid-state polymerization reactivity even at an ambient temperature without light. If the alkyl groups are attached to higher oligoyne compounds with a conjugated acetylene number greater than six, handling them is difficult because of their high reactivity. On the other hand, when the alkylurethane groups were introduced in a higher oligoyne compound, the solubility of the monomer was low and the handling was also difficult. ${ }^{25}$ Thus, appropriate substituents are required for higher oligoynes. Therefore, three hexayne derivatives with different end groups were synthesized in this study. The substituents attached were $-\left(\mathrm{CH}_{2}\right)_{9}$-OX, in which the methylene number between the acetylenic group and oxygen was increased from five in the former alkylurethane derivative to nine for higher solubility. With 


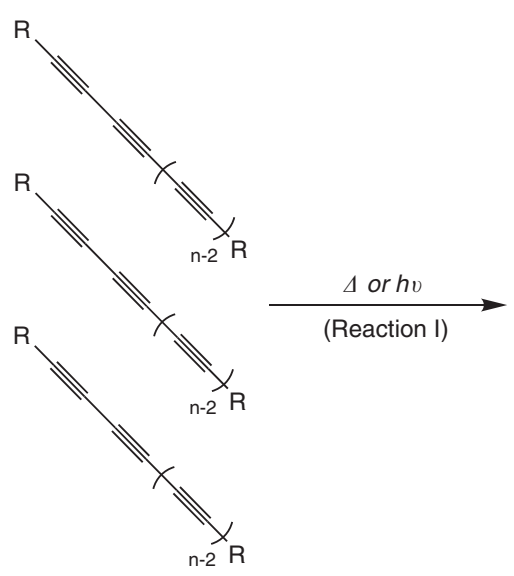

Monomer

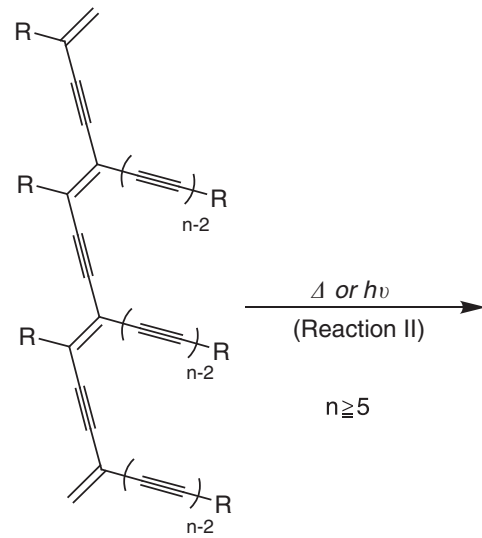

Linear PDA

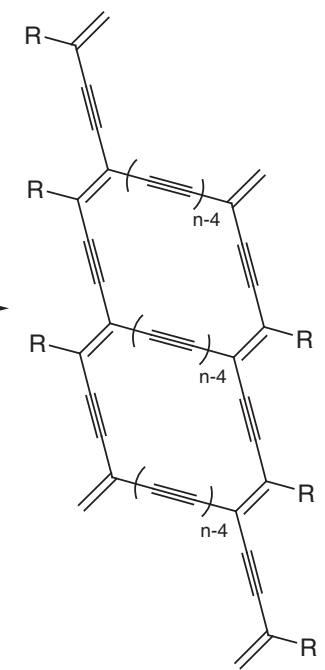

Ladder-type PDA

Figure 1 Solid-state polymerization scheme of oligoyne compounds.

the original hexaynediol compound $\mathbf{1}(\mathrm{X}=\mathrm{H})$, phenyl isocyanate or benzoic acid was reacted to give the corresponding $N$-phenyl urethane 2 and phenyl ester 3, respectively. The solid-state polymerization behaviors of these three compounds were investigated using infrared (IR), ultraviolet-visible-near-IR and ${ }^{13} \mathrm{C}-\mathrm{NMR}$ spectroscopies and $\mathrm{X}$-ray diffraction (XRD).

\section{EXPERIMENTAL PROCEDURE}

\section{Apparatus}

Melting points were measured using a Yanaco MP-500P micro melting-point apparatus (Yanaco, Kyoto, Japan) without correction. IR spectra were recorded for KBr-pelletized samples on a Horiba FT-210 spectrometer (Horiba, Kyoto, Japan). ${ }^{1} \mathrm{H}$ - and ${ }^{13} \mathrm{C}$-NMR spectra were measured using a JEOL JNM-EX270 spectrometer or a JEOL JNM-ECX 400 spectrometer (Jeol, Akishima, Japan). For solid-state ${ }^{13} \mathrm{C}$-NMR spectra, CP/MAS, dipolar dephasing and their TOSS spectra were obtained using the JEOL JNM-ECX 400 spectrometer (Jeol). Ultraviolet-visible-near-IR diffuse reflectance spectra were recorded on a JASCO V-570 spectrophotometer (Jasco, Hachioji, Japan) equipped with an ILN-472 integrating sphere. For spectral measurements, monomer crystals were mixed with potassium bromide, ground and placed into a quartz-window cell. Powder XRD patterns were recorded on a Rigaku Ultima-XG/YP diffractometer (Rigaku, Akishima, Japan) using $\mathrm{Cu} K_{\alpha}$ radiation.

\section{Synthesis of monomers}

14-Methyl-10,12-pentadecadiyne-1,14-diol 6. Isopropylamine $(11 \mathrm{ml})$ and copper(I) chloride $(143 \mathrm{mg})$ were added to a solution of 10-undecyn-1-ol 4 $(4.44 \mathrm{~g}, 26.4 \mathrm{mmol})$ in methanol $(5 \mathrm{ml})$ under a nitrogen atmosphere at ambient temperature. After the mixture was stirred for $5 \mathrm{~min}$, 4-bromo-2methyl-3-butyn-2-ol $5(5.31 \mathrm{~g}, 31.0 \mathrm{mmol})$ was added dropwise to the solution for $5 \mathrm{~h}$. When the reaction mixture turned blue on addition of $\mathbf{5}$, a sufficient amount of hydroxylamine hydrochloride was added until the mixture turned reddish brown. After the addition of $\mathbf{5}$ was completed, the mixture was stirred overnight and the solvent was evaporated under reduced pressure. Dilute hydrochloric acid was added to the reaction mixture until it turned acidic and it was extracted using chloroform. The organic layer was dried over anhydrous magnesium sulfate. After filtration, the filtrate was concentrated under reduced pressure. The residue was purified by column chromatography (silica gel, chloroform-ethyl acetate $(9: 1))$ to yield $6(2.50 \mathrm{~g}, 39 \%)$ as a yellow oil: ${ }^{1} \mathrm{H}-\mathrm{NMR}\left(270 \mathrm{MHz}, \mathrm{CDCl}_{3}\right) \delta 1.24-1.57(14 \mathrm{H}, \mathrm{m}), 1.53(6 \mathrm{H}, \mathrm{s}), 2.23(2 \mathrm{H}, \mathrm{t}$, $J=7.0 \mathrm{~Hz}), 3.64(2 \mathrm{H}, \mathrm{t}, J=6.6 \mathrm{~Hz})$, the protons of the hydroxyl groups were not clearly detected; ${ }^{13} \mathrm{C}-\mathrm{NMR}\left(67.5 \mathrm{MHz}, \mathrm{CDCl}_{3}\right) \delta 19.09,25.53,27.92,28.45$, 28.70, 29.12, 29.17, 31.03, 32.53, 62.69, 64.35, 65.17, 67.02, 79.98, 81.53.

10,12-Tridecadiyn-1-ol 7. Powdered potassium hydroxide $(0.45 \mathrm{~g}, 8 \mathrm{mmol})$ was added to a solution of $6(2.00 \mathrm{~g}, 8 \mathrm{mmol})$ in toluene $(25 \mathrm{ml})$, and the mixture was heated at $80^{\circ} \mathrm{C}$ for $2 \mathrm{~h}$. After filtration of the mixture, the filtrate was concentrated under reduced pressure. The residue was purified by column chromatography (silica gel, chloroform-ethyl acetate $(9: 1))$ to yield $7(1.22 \mathrm{~g}$, $79 \%)$ as a yellow oil: ${ }^{1} \mathrm{H}-\mathrm{NMR}\left(270 \mathrm{MHz}, \mathrm{CDCl}_{3}\right) \delta 1.29-1.40(10 \mathrm{H}, \mathrm{m}), 1.50$ $1.58(4 \mathrm{H}, \mathrm{m}), 1.97(1 \mathrm{H}, \mathrm{t}, J=1.2 \mathrm{~Hz}), 2.26(2 \mathrm{H}, \mathrm{dt}, J=1.2,6.9 \mathrm{~Hz}), 3.64(2 \mathrm{H}, \mathrm{t}$, $J=6.7 \mathrm{~Hz}$ ), the protons of the hydroxyl groups were not clearly detected; ${ }^{13} \mathrm{C}-\mathrm{NMR}\left(67.5 \mathrm{MHz}, \mathrm{CDCl}_{3}\right) \delta 18.92,25.66,27.93,28.72,28.92,29.30$, $29.35,32.73,63.01,64.45,64.61,68.46,78.52$.

16-Methyl-10,12,14-heptadecatriyne-1,16-diol 8. Isopropylamine $(30 \mathrm{ml})$ and copper(I) chloride $(82 \mathrm{mg})$ were added to a solution of $7(0.76 \mathrm{~g}, 4.00 \mathrm{mmol})$ in methanol $(5 \mathrm{ml})$ under a nitrogen atmosphere at ambient temperature. After stirring for $5 \mathrm{~min}$, 4-bromo-2-methyl-3-butyn-2-ol 5 ( $1.04 \mathrm{~g}, 6.40 \mathrm{mmol})$ was added dropwise to the solution for $2 \mathrm{~h}$. The further experimental procedure was exactly the same as the synthesis of $\mathbf{6}$, and $0.39 \mathrm{~g}$ of $\mathbf{8}(36 \%)$ was obtained as a white powder: ${ }^{1} \mathrm{H}-\mathrm{NMR}\left(270 \mathrm{MHz}, \mathrm{CDCl}_{3}\right) \delta 1.28-1.59(14 \mathrm{H}, \mathrm{m}), 1.54(6 \mathrm{H}, \mathrm{s})$, $2.30(2 \mathrm{H}, \mathrm{t}, J=7.1 \mathrm{~Hz}), 3.56(2 \mathrm{H}, \mathrm{t}, J=6.6 \mathrm{~Hz})$, the protons of the hydroxyl groups were not clearly detected; ${ }^{13} \mathrm{C}-\mathrm{NMR}\left(67.5 \mathrm{MHz}, \mathrm{CDCl}_{3}\right) \delta 19.39,25.66$, $27.88,28.71,28.87,29.29,29.32,31.00,32.74,58.91,63.05,64.44,65.40,65.52$, $67.57,80.89,81.30$.

10,12,14-Pentadecatriyn-1-ol 9. Powdered potassium hydroxide $(0.16 \mathrm{~g}$, $2.80 \mathrm{mmol})$ was added to a solution of $8(0.38 \mathrm{~g}, 1.40 \mathrm{mmol})$ in toluene $(23 \mathrm{ml})$, and the mixture was heated at $80^{\circ} \mathrm{C}$ for $2 \mathrm{~h}$. After filtration of the mixture, the filtrate was concentrated under reduced pressure. The residue was purified by column chromatography (silica gel, chloroform-ethyl acetate (9:1)) to yield $\mathbf{9}$ in chloroform. Since the oily compound $\mathbf{9}$ has a high reactivity in its pure state, it was stored in solution. Spectroscopic data for $\mathbf{9}$ were as follows: ${ }^{1} \mathrm{H}-\mathrm{NMR}\left(270 \mathrm{MHz}, \mathrm{CDCl}_{3}\right) \delta 1.29-1.40(10 \mathrm{H}, \mathrm{m}), 1.50-1.58(4 \mathrm{H}, \mathrm{m}), 2.04$ $(1 \mathrm{H}, \mathrm{s}), 2.29(2 \mathrm{H}, \mathrm{t}, J=7.1 \mathrm{~Hz}), 3.64(2 \mathrm{H}, \mathrm{t}, J=6.6 \mathrm{~Hz})$, the protons of the hydroxyl groups were not clearly detected; ${ }^{13} \mathrm{C}-\mathrm{NMR}\left(67.5 \mathrm{MHz}, \mathrm{CDCl}_{3}\right)$ $\delta 19.27,25.66,27.84,28.73,28.90,29.29,29.33,32.72,59.42,62.99,64.15$, $65.21,65.85,68.63,80.26$.

10,12,14,16,18,20-Triacontane-1,30-diol 1 . Compound $\mathbf{9}(1.3 \mathrm{~g}, 5.9 \mathrm{mmol})$ was added to a solution of copper(I) chloride $(7 \mathrm{mg})$ and $N, N, N^{\prime}, N^{\prime}$-tetramethylethylenediamine $(10 \mathrm{mg})$ in tetrahydrofuran $(10 \mathrm{ml})$. Oxygen was bubbled into the reaction mixture for $20 \mathrm{~h}$ at ambient temperature. After evaporation of the 
solvent under reduced pressure, the mixture was acidified with dilute hydrochloric acid and extracted with chloroform. The organic layer was dried over anhydrous magnesium sulfate. After filtration, the solvent in the filtrate was evaporated under reduced pressure. The residue was purified by column chromatography (silica gel, chloroform-tetrahydrofuran $(3: 2)$ ) to yield $\mathbf{1}$ $(757 \mathrm{mg}, 60 \%)$ as a white powder: melting point: $103-105^{\circ} \mathrm{C} .{ }^{1} \mathrm{H}-\mathrm{NMR}$ $\left(400 \mathrm{MHz}\right.$, dimethylsulfoxide at $\left.100^{\circ} \mathrm{C}\right): \delta 1.31-1.46(20 \mathrm{H}, \mathrm{m}), 1.51-1.59$ $(4 \mathrm{H}, \mathrm{m}), 1.73-1.80(4 \mathrm{H}, \mathrm{m}), 2.46(4 \mathrm{H}, \mathrm{t}, J=6.9 \mathrm{~Hz}), 4.31(4 \mathrm{H}, \mathrm{t}, J=6.4 \mathrm{~Hz})$, the protons of the hydroxyl groups were not clearly detected. ${ }^{13} \mathrm{C}-\mathrm{NMR}$ $\left(100 \mathrm{MHz}\right.$, dimethylsulfoxide at $100^{\circ} \mathrm{C}$ ): $\delta 18.40,25.13,26.84,27.89$ (two carbons), 27.94, 28.47, 32.21, 59.28, 60.55, 60.90, 62.24, 63.26, 64.38, 84.49. IR (KBr): 3400, 2931, 2850, 2197, $2168 \mathrm{~cm}^{-1}$. Found: C, 80.42; H, 9.08\%. Calculated for $\mathrm{C}_{30} \mathrm{H}_{38} \mathrm{O}_{2} \mathrm{H}_{2} \mathrm{O}$ : C, 80.31; H, 8.99\%.

10,12,14,16,18,20-Triacontahexayne-1,30-diyl bis(N-phenyl)carbamate 2 . Phenyl isocyanate $(476 \mathrm{mg}, 4.0 \mathrm{mmol})$ and two drops of dibutyltin dilaurate were added to a solution of $\mathbf{1}(757 \mathrm{mg}, 1.8 \mathrm{mmol})$ in toluene $(300 \mathrm{ml})$. The mixture was stirred overnight at ambient temperature. After the evaporation of the solvent under reduced pressure, the residue was purified by column chromatography (silica gel, chloroform-tetrahydrofuran (3:2)) to yield $2(673 \mathrm{mg}, 56 \%)$ as a green powder, the color of which was because of partial polymerization. melting point: $108-110{ }^{\circ} \mathrm{C}$. ${ }^{1} \mathrm{H}-\mathrm{NMR}\left(400 \mathrm{MHz}\right.$, dimethylsulfoxide at $\left.100{ }^{\circ} \mathrm{C}\right)$ : $\delta$ 1.29-1.35 (20H, m), 1.46-1.53 (4H, m), 1.57-1.64 $(4 \mathrm{H}, \mathrm{m}), 2.44(4 \mathrm{H}, \mathrm{t}$, $J=6.9 \mathrm{~Hz}), 4.06(4 \mathrm{H}, \mathrm{t}, J=6.9 \mathrm{~Hz}), 6.96(2 \mathrm{H}, \mathrm{t}, J=7.4 \mathrm{~Hz}), 7.25(4 \mathrm{H}, \mathrm{dd}, J=7.4$, $7.8 \mathrm{~Hz}), 7.43(4 \mathrm{H}, \mathrm{d}, J=7.8 \mathrm{~Hz}), 9.43\left(2 \mathrm{H}\right.$, br s). ${ }^{13} \mathrm{C}-\mathrm{NMR}(100 \mathrm{MHz}$, dimethylsulfoxide at $100{ }^{\circ} \mathrm{C}$ ): $\delta 18.36,24.95,26.78,27.81$ (two carbons), $28.13,28.23,28.26,59.28,60.91,62.25,63.28,63.85,64.36,84.49,118.28$, 121.97, 128.18, 138.93, 153.40. IR (KBr): 3309, 2924, 2854, 2198, 2168, 1697, $1535 \mathrm{~cm}^{-1}$. Found: C, 78.64; H, 7.40; N, 4.19\%. Calculated for $\mathrm{C}_{44} \mathrm{H}_{48} \mathrm{~N}_{2} \mathrm{O}_{4}$ : C, $79.01 ; \mathrm{H}, 7.23 ; \mathrm{N}, 4.19 \%$

10,12,14-Pentadecatriynyl benzoate 10. N,N'-dicyclohexylcarbodiimide $(1.15 \mathrm{mg}$, $5.6 \mathrm{mmol}), 9(1.0 \mathrm{~g}, 4.6 \mathrm{mmol})$ and 4 -(dimethylamino)pyridine $(68 \mathrm{mg}$, $0.56 \mathrm{mmol})$ were added to a solution of benzoic acid $(678 \mathrm{mg}, 5.6 \mathrm{mmol})$ in dichloromethane $(50 \mathrm{ml})$ at $0{ }^{\circ} \mathrm{C}$ under a nitrogen atmosphere. The mixture was then refluxed for $3 \mathrm{~h}$. After filtration, the filtrate was acidified with dilute hydrochloric acid and extracted with dichloromethane. The organic layer was dried over anhydrous magnesium sulfate. After filtration, the filtrate was concentrated under reduced pressure. The residue was purified by column chromatography (silica gel, chloroform) to yield $\mathbf{1 0}$ in chloroform. Since the oily compound $\mathbf{1 0}$ has high reactivity in its pure state, it was stored in solution. Spectroscopic data for 10 were as follows: ${ }^{1} \mathrm{H}-\mathrm{NMR}\left(400 \mathrm{MHz}, \mathrm{CDCl}_{3}\right) \delta 1.24$ $1.44(10 \mathrm{H}, \mathrm{m}), 1.51-1.56(2 \mathrm{H}, \mathrm{m}), 1.73-1.79(2 \mathrm{H}, \mathrm{m}), 2.17(1 \mathrm{H}, \mathrm{s}), 2.29(2 \mathrm{H}, \mathrm{t}$, $J=7.1 \mathrm{~Hz}), 4.32(2 \mathrm{H}, \mathrm{t}, J=6.6 \mathrm{~Hz}), 7.44(2 \mathrm{H}, \mathrm{dd}, J=7.4,7.2 \mathrm{~Hz}), 7.56(1 \mathrm{H}, \mathrm{t}$, $J=7.4 \mathrm{~Hz}), 8.04(2 \mathrm{H}, \mathrm{d}, J=7.2 \mathrm{~Hz}) ;{ }^{13} \mathrm{C}-\mathrm{NMR}\left(100 \mathrm{MHz}, \mathrm{CDCl}_{3}\right) \delta 19.52,25.98$, $27.81,28.69,28.77,28.90,29.16,29.26,60.40,61.50,62.40,62.75,65.06,65.69$, $81.86,128.29,129.50,130.48,132.77,166.65$

10,12,14,16,18,20-Triacontahexayne-1,30-diyl dibenzoate 3. Compound 10 (1.0 g, $3.1 \mathrm{mmol}$ ) was added to a solution of copper(I) chloride $(31.0 \mathrm{mg})$ and $N, N, N^{\prime}, N^{\prime}$-tetramethylethylenediamine $(36.3 \mathrm{mg})$ in chloroform $(50 \mathrm{ml})$. Oxygen was bubbled into the reaction mixture for $24 \mathrm{~h}$ at ambient temperature. After evaporation of the solvent under reduced pressure, dilute hydrochloric acid was added until the mixture turned acidic, and the mixture was extracted with chloroform. The organic layer was dried over anhydrous magnesium sulfate. After filtration, the solvent was evaporated under reduced pressure. The residue was purified by column chromatography (silica gel, chloroform) to yield 3 ( $320 \mathrm{mg}$, $32 \%)$ as yellow crystals: melting point: $81-82{ }^{\circ} \mathrm{C}$. ${ }^{1} \mathrm{H}-\mathrm{NMR}\left(400 \mathrm{MHz}, \mathrm{CDCl}_{3}\right)$ : $\delta$ 1.31-1.46 (20H, m), 1.51-1.59 (4H, m); 1.73-1.80 $(4 \mathrm{H}, \mathrm{m}), 2.32(4 \mathrm{H}, \mathrm{t}$, $J=7.0 \mathrm{~Hz}), 4.31(4 \mathrm{H}, \mathrm{t}, J=7.0 \mathrm{~Hz}), 7.44(4 \mathrm{H}, \mathrm{dd}, J=7.4,7.2 \mathrm{~Hz}), 7.56(2 \mathrm{H}, \mathrm{t}$, $J=7.4 \mathrm{~Hz}), 8.04(4 \mathrm{H}, \mathrm{d}, J=7.2 \mathrm{~Hz}) .{ }^{13} \mathrm{C}-\mathrm{NMR}\left(100 \mathrm{MHz}, \mathrm{CDCl}_{3}\right): \delta 19.52,25.98$, $27.81,28.69,28.77,28.90,29.16,29.26,60.40,61.50,62.40,62.75,65.06,65.69$, $81.86,128.31,129.52,130.51,132.80,166.68$. IR (KBr): 2924, 2850, 2195, 2166 , $1716 \mathrm{~cm}^{-1}$. Found: C, 82.97; $\mathrm{H}, 7.36 \%$. Calculated for $\mathrm{C}_{44} \mathrm{H}_{46} \mathrm{O}_{4}: \mathrm{C}, 82.72$; $\mathrm{H}, 7.26 \%$.

\section{RESULTS AND DISCUSSION}

Hexayne compounds were synthesized according to Figure 2. The heterocoupling reaction between an acetylenic compound with a 9hydroxynonyl group and 4-bromo-2-methyl-3-butyn-2-ol 5 and the following acetone elimination reaction were repeated twice to yield terminal triyne alcohol $\mathbf{9}$. The oxidative coupling reaction of the alcohol yielded hexaynediol $\mathbf{1}$. The addition of $\mathbf{1}$ to phenyl isocyanate gave urethane derivative 2. Ester derivative $\mathbf{3}$ was prepared by the other route, that is, esterification of 9 , followed by oxidative coupling, because the yield of esterification of 1 was quite low.

Monomers 1-3 were thermally polymerizable since the heated samples became insoluble. Thus, we first measured IR spectra during heating. All monomers showed peaks corresponding to the stretching vibration of $\mathrm{C} \equiv \mathrm{C}\left(v_{\mathrm{C} \equiv \mathrm{C}}\right)$ at around 2200 and $2170 \mathrm{~cm}^{-1}$, and the peak intensity decreased with heating time, indicating that $\mathrm{C} \equiv \mathrm{C}$ reacted during polymerization. All final products from monomers by heating showed almost no $v_{\mathrm{C} \equiv \mathrm{C}}$ peaks. Thus, from this peak reduction, we obtained monomer conversions to final polymers depending on the heating time as shown in Figure 3 . Since the melting points of $\mathbf{1}, 2$ and 3 are $103-105,108-110$ and $81-82^{\circ} \mathrm{C}$, respectively, the heating temperature for the polymerization of $\mathbf{1}$ and $\mathbf{2}$ was set to $80^{\circ} \mathrm{C}$ and that of 3 was $60^{\circ} \mathrm{C}$. In order to avoid the effect of photoirradiation, samples were kept in a dark place during heating. The order of the reaction rates at the initial stage of polymerization was $2>1>3$. Among them, the low reaction rate of $\mathbf{3}$ is understandable because the reaction temperature was low. In Figure 3 , the measured points for $\mathbf{1}$ and $\mathbf{2}$ can be roughly fitted by exponential curves. On the other hand, the measured points for 3 cannot be approximated to a simple exponential curve. As mentioned later, structural disorder during solid-state polymerization was found for $\mathbf{3}$ from the first step of polymerization (reaction I in Figure 1), and the disordered arrangement may have a different polymerization rate. Although the behavior of the IR peak reduction was the same as that of the alkyl-substituted hexayne compound studied previously, ${ }^{20}$ color changes during polymerization differed among monomers.

Polymerized samples of $\mathbf{1}$ and $\mathbf{2}$ showed a green color, whereas $\mathbf{3}$ became red at the initial stage of polymerization. Since polymer $\pi$-conjugated structures should reflect the absorption spectra of polymers, ultraviolet-visible-near-IR diffuse reflectance spectra were recorded at the initial stage of thermal polymerization. As shown in Figure 4, 1 showed an absorption increase in the wavelength region less than $800 \mathrm{~nm}$, and an absorption maximum was observed at around $730 \mathrm{~nm}$. This absorption spectrum is characteristic for PDA with tetraynyl substituents obtained via reaction I in Figure $1,{ }^{20}$ and the maximum wavelength is apparently bathochromic-shifted compared with the excitonic absorption peak of conventional PDAs in the range of 520-640 nm. In Figure 5, the absorption maximum of the largest peak for 2 is also located at about $730 \mathrm{~nm}$. However, the absorption tail of 2 extends to the near-IR region, and broad absorption bands were observed at about 980 and $860 \mathrm{~nm}$. These broad peaks have also been observed in alkyl- and alkylurethanesubstituted hexayne derivatives, and we proposed that these near-IR bands, which appeared in a region with longer wavelengths than the excitonic band, originated from the ladder polymer, in which two PDA backbones are connected with conjugated acetylenes through reaction II in Figure 1..$^{20,21}$ Since $\mathbf{1}$ did not show absorption bands in the near-IR region, polymers from 1 have a linear PDA structure, whereas 2 gave the ladder-type PDA. As shown in Figure 3, the peaks corresponding to the $v_{\mathrm{C} \equiv \mathrm{C}}$ of $\mathbf{1}$ finally disappeared, indicating that tetraynyl substituents attached to PDA in the linear polymer from 1 reacted with further heating. However, this reaction occurred 


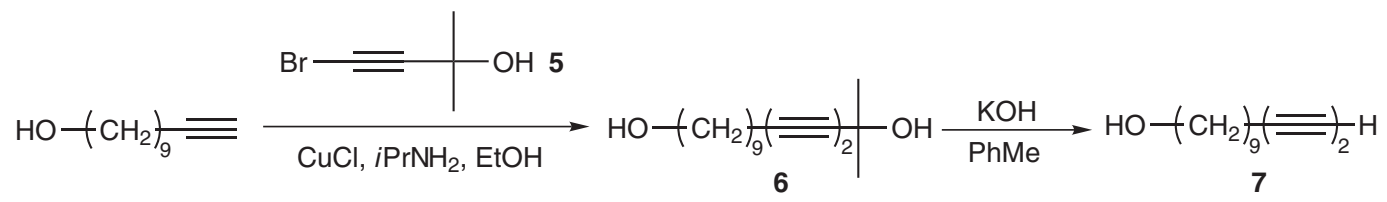

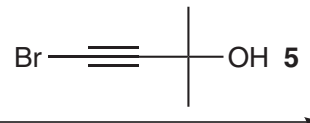

$\mathrm{CuCl}, i \mathrm{PrNH}_{2}, \mathrm{EtOH}$
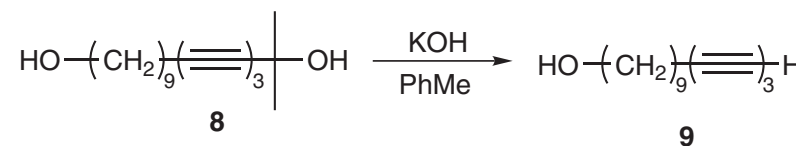

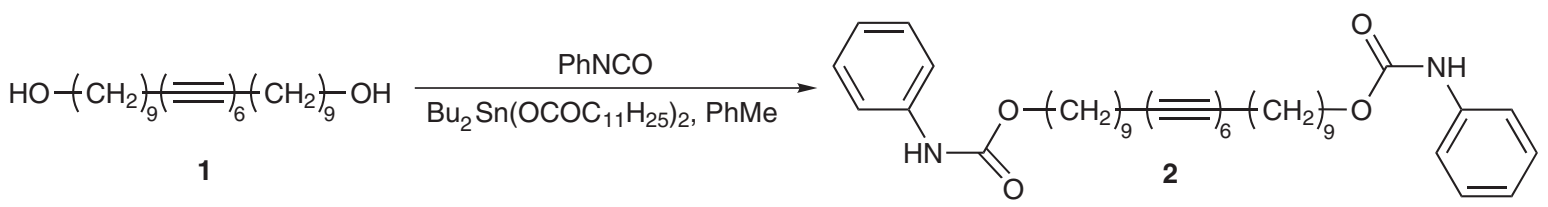

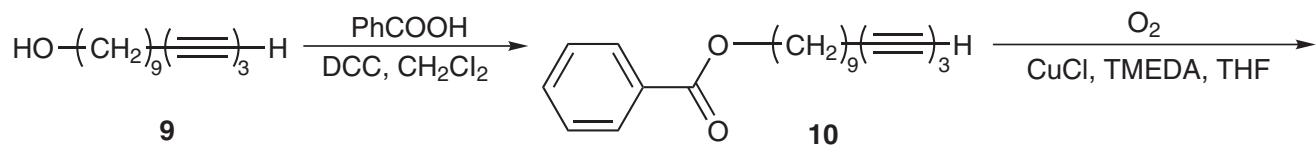<smiles>CC(C)(C)CCOC(=O)c1ccccc1</smiles>

Figure 2 Synthesis scheme of hexayne monomers $\mathbf{1}-\mathbf{3}$.

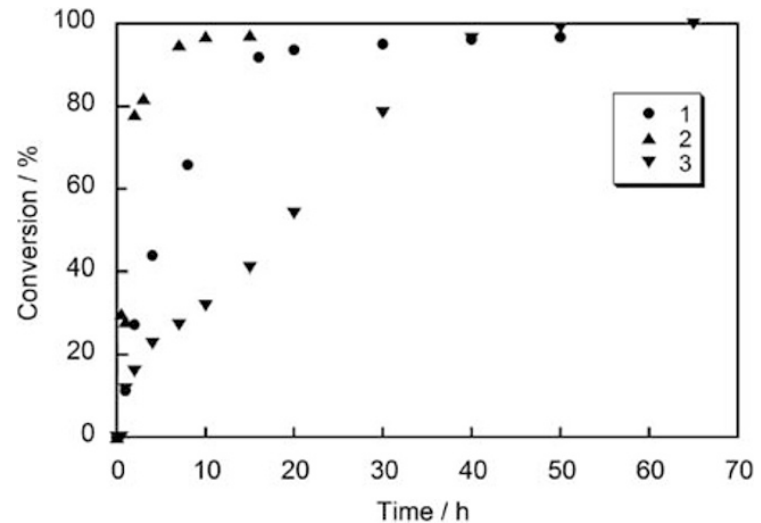

Figure $\mathbf{3}$ Time-conversion curves of $\mathbf{1 - 3}$ when heated. The heating temperature of $\mathbf{1}$ and $\mathbf{2}$ was $80^{\circ} \mathrm{C}$, whereas that of $\mathbf{3}$ was $60^{\circ} \mathrm{C}$.

in an irregular manner because no near-IR absorption assigned to the ladder-type PDA structure was observed. Figure 6 shows the diffuse reflectance spectra of 3 , which are quite different from those of 1 and 2. There is no characteristic excitonic band for PDA, and 3 showed only an increase in the visible region less than $\sim 800 \mathrm{~nm}$. This type of spectral change has often been observed for compounds with irregular polymerization or oligomerization, irrespective of conversion. ${ }^{26,27}$ Thus, we can conclude that polymerization is not regularly controlled for 3 in the initial stage of polymerization, but reactions continue until the peaks assigned to $v_{\mathrm{C} \equiv \mathrm{C}}$ almost disappear.

Since the formation of the ladder-type PDA was suggested for 2 from the electronic structure, its polymer structure was further

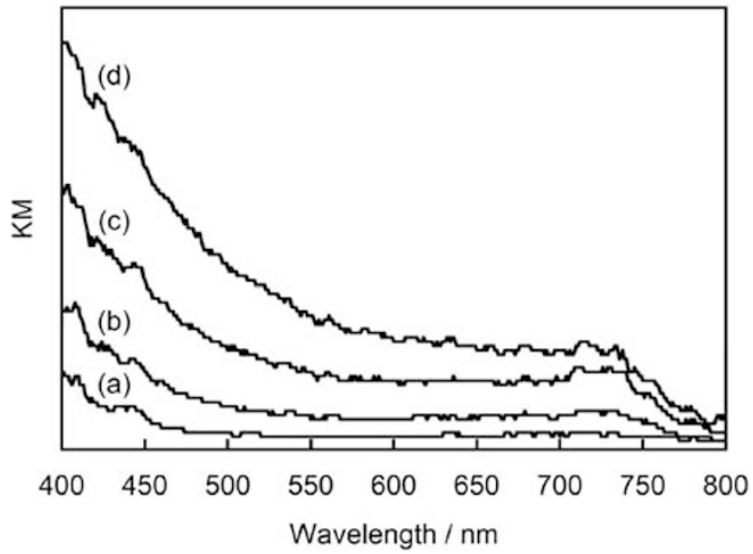

Figure 4 Variation in the diffuse reflectance spectra of $\mathbf{1}$ with heating time: (a) $0 \mathrm{~h}$, (b) $1 \mathrm{~h}$, (c) $3 \mathrm{~h}$ and (d) $7 \mathrm{~h}$.

confirmed by a solid-state ${ }^{13} \mathrm{C}-\mathrm{NMR}$ spectral study (Figure 7). With heating, the peaks in the range of 63-83 p.p.m. were reduced and finally disappeared except for the peak at 66.3 p.p.m. This indicates that acetylenic carbons were transferred to other types of carbons, and only the methylene carbons adjacent to oxygen atoms remained. The peak at 21.6 p.p.m. (peak A) corresponding to methylene carbons adjacent to acetylenic carbons also decreased. In the heated sample, a new peak at 37.4 p.p.m. (peak B) corresponding to methylene carbons adjacent to olefinic carbons appeared. These changes suggest that acetylenic moieties directly attached to methylene chains reacted to become olefinic structures. In addition, several peaks appeared in the range of 103-110 p.p.m. (peaks C) and around 129 p.p.m. (peak D), and they were assigned to the carbons of the $\pi$-conjugated structure 


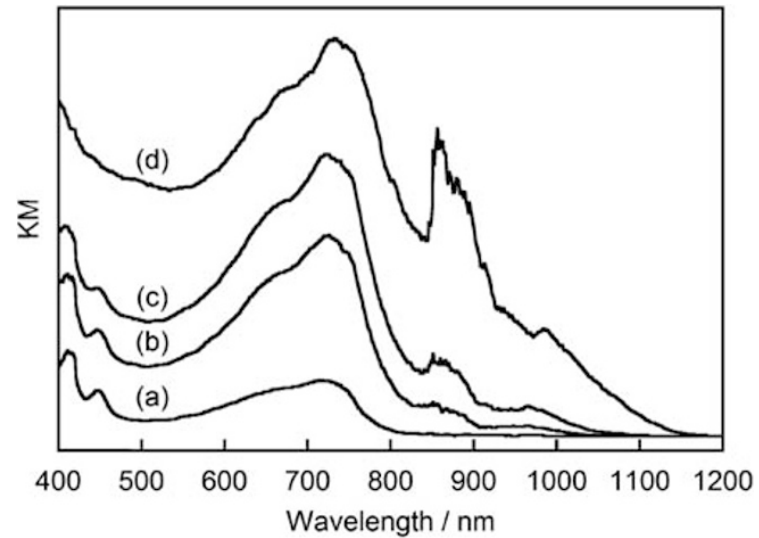

Figure 5 Variation in the diffuse reflectance spectra of 2 with heating time: (a) $0 \mathrm{~h}$, (b) $0.5 \mathrm{~h}$, (c) $1 \mathrm{~h}$ and (d) $3 \mathrm{~h}$. The large step at $850 \mathrm{~nm}$ in the spectrum for a heating time of $3 \mathrm{~h}$ is an artifact because of instrumental issues.

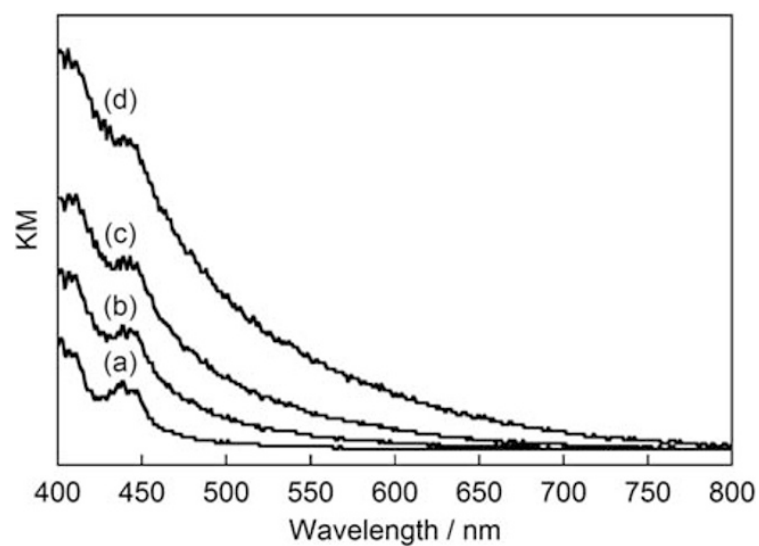

Figure 6 Variation in diffuse reflectance spectra of $\mathbf{3}$ with heating time: (a) $0 \mathrm{~h}$, (b) $3 \mathrm{~h}$, (c) $7 \mathrm{~h}$ and (d) $15 \mathrm{~h}$.

produced. From these results, the polymerization scheme of $\mathbf{2}$ was confirmed as shown in Figure 1 to give the ladder-type PDA through reactions I and II. Since the peaks were gradually broadened and weakened by heating in general, disorder during polymerization is also suggested. In the solid-state ${ }^{13} \mathrm{C}-\mathrm{NMR}$ spectra of $\mathbf{1}$ and $\mathbf{3}$ during thermal polymerization, the peaks of acetylenic carbons and methylene carbons adjacent to acetylenic carbons also decreased. However, the appearance of new peaks was not clearly observed, indicating that the structural disorder of the final polymers from $\mathbf{1}$ and $\mathbf{3}$ was quite large.

In XRD experiments of polymers from $\mathbf{1}$ and $\mathbf{3}$, clear diffraction peaks were not observed at all. These facts are consistent with the nuclear magnetic resonance results described above. On the other hand, relatively ordered structures of the polymer from 2 were recognized by XRD patterns as shown in Figure 8. In monomer crystals of 2, a layered structure with an interlayer spacing of $3.00 \mathrm{~nm}$ was found from the progression in $2 \theta$ angles between 3 and $16^{\circ}$ These progression peaks gradually shifted to smaller $2 \theta$ angles during polymerization, and they were still present with an interlayer spacing of $3.30 \mathrm{~nm}$ even after heating for $13 \mathrm{~h}$. However, the progression peaks at higher angles became small, and the sharp peaks from 18 to $28^{\circ}$ of the monomer, which are related to the monomer stack within the layer, almost disappeared. These results indicate that the interlayer

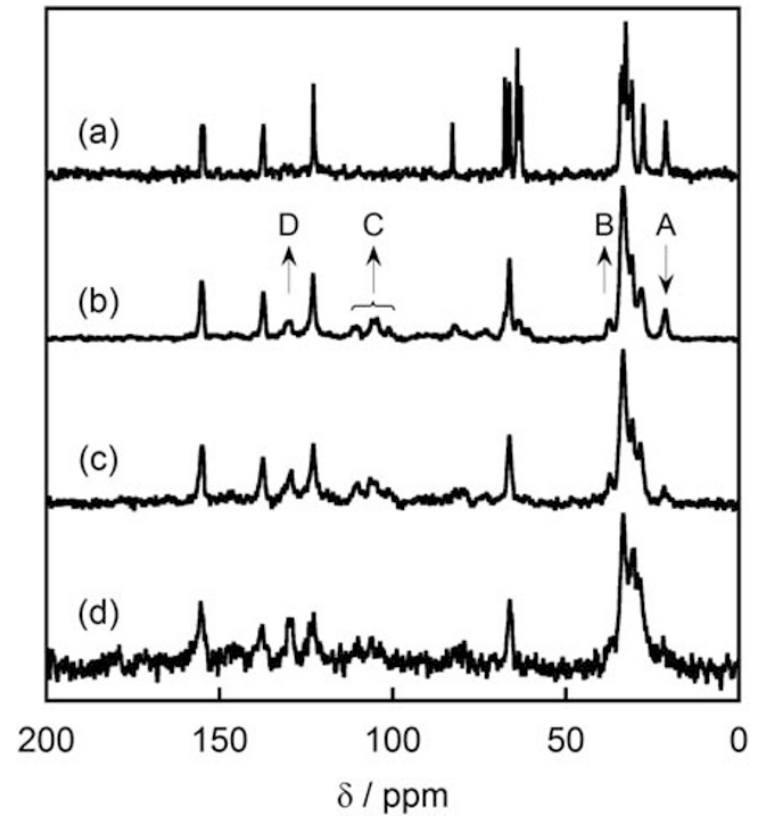

Figure 7 Variation in the solid-state ${ }^{13} \mathrm{C}$-NMR spectra (TOSS) of 2 with heating time: (a) $0 \mathrm{~h}$, (b) $4 \mathrm{~h}$, (c) $8 \mathrm{~h}$ and (d) $13 \mathrm{~h}$.

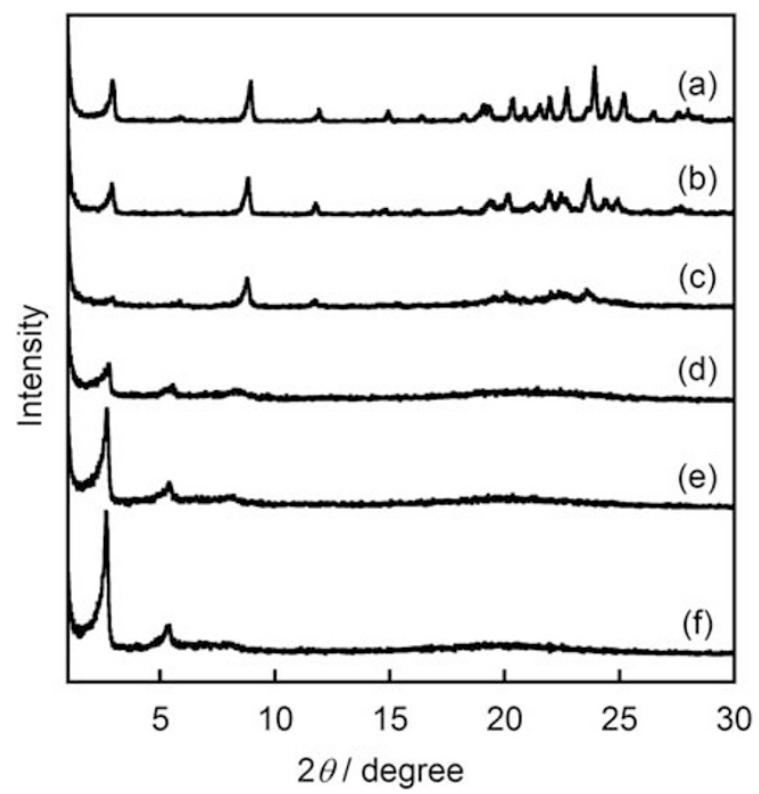

Figure 8 Variation in the X-ray diffractograms of $\mathbf{2}$ with heating time: (a) $0 \mathrm{~h}$, (b) $0.5 \mathrm{~h}$, (c) $1 \mathrm{~h}$, (d) $2 \mathrm{~h}$, (e) $4 \mathrm{~h}$ and (f) $8 \mathrm{~h}$. The diffractogram after $13 \mathrm{~h}$ was similar to that after $8 \mathrm{~h}$.

structure of 2 was still maintained, but the in-plane structure deteriorated after polymerization.

Although the crystal structures of the compounds in this study could not be clarified because of the poor quality of their crystals for $\mathrm{X}$-ray crystallography, differences in the polymerization behaviors among them can be estimated from the results of previous studies and the solved crystal structures of related compounds. Regular polymerization in two steps was observed only for $\mathbf{2}$ with urethane groups. Generally, symmetrically substituted butadiyne derivatives with two urethane groups often give two arrays of intermolecular 
hydrogen bonding within a monomer array. ${ }^{6,28-30}$ Thus, 2 seems not to be an exception, and the strong intermolecular hydrogen bonding in one direction helps to maintain the regular structure even after forming the ladder-type PDA. Previously, the visible-near-IR spectrum of the polymer from a hexayne compound with substituents of $\left(\mathrm{CH}_{2}\right)_{5}-\mathrm{O}-\mathrm{CO}-\mathrm{NH}-\mathrm{C}_{6} \mathrm{H}_{5}$, that is, a homolog of 2 with a different methylene number, was studied, and clear broad bands in the near-IR region were not detected, although excitonic bands appeared. ${ }^{21}$ In this case, linear PDA was formed, and the methylene number between the acetylene and urethane moieties seems to determine whether the ladder-type PDA is formed. Sufficient flexibility around the conjugated acetylenic group is also necessary for ladder polymer synthesis.

Intermolecular hydrogen bonding is also possible for alcohol derivatives, and it may help to align $\mathbf{1}$ into a polymerizable stack. For the $\mathrm{O}-\mathrm{H}$ stretching vibration in the IR spectrum of 1 , a broad band was observed at $3200-3700 \mathrm{~cm}^{-1}$, in addition to a sharp peak at $3640 \mathrm{~cm}^{-1}$, and the broad band indicates the intermolecular hydrogen-bond formation. However, intermolecular hydrogen bonding between hydroxyl groups is often observed across adjacent two molecular arrays. ${ }^{31,32}$ This type of network interaction may increase the disorder in crystals during two-step polymerization because disorder in one molecular array causes disorder in the adjacent two molecular arrays. This is one of the plausible explanations for the polymerization behavior of $\mathbf{1}$, which shows regular polymerization in the first step and disordered polymerization in the second step.

On the other hand, ester $\mathbf{3}$ showed disordered polymerization from the first step. In the previous study, butadiyne and tetrayne derivatives modified by phenoxycarbonylpropyl groups or phenoxycarbonylbutyl groups at both ends were prepared..$^{33}$ Among them, butadiyne derivatives showed no solid-state reactivities, and no common molecular conformation or crystal structure was found. This is because of the lack of functional groups for directional control of molecular alignment in these ester compounds. Butadiyne derivatives with benzoyloxy groups at the ends were also reported to give unreactive crystals under atmospheric pressure. ${ }^{34,35}$ However, in the tetrayne compound with phenoxycarbonylpropyl groups, its solidstate polymerization was confirmed. In this case, the long rigid rod structure of the tetrayne moiety enforced the monomer molecule stacking. Similarly, the hexayne moiety seems to yield a polymerizable stack in ester 3. However, a lack of strong interaction, such as hydrogen bonding between monomers, resulted in disorder during polymerization.

\section{CONCLUSION}

Three conjugated hexayne compounds with different end groups 1-3 were synthesized, and their solid-state polymerization was investigated. The polymerization of these compounds could be performed by heating, and all compounds showed solid-state polymerization. The polymerization of ester 3 proceeded in an irregular manner from the initial stages of polymerization, because ester groups have no strong intermolecular interaction and molecular alignment may be easily disordered during polymerization. After the initial stages of polymerization, alcohol 1 and urethane 2 showed excitonic absorption bands at around $730 \mathrm{~nm}$, indicating the formation of the linear PDA structure. Since these compounds have hydrogen-bonding functional groups such as hydroxyl or urethane groups, monomer stacking was properly arranged to yield polymerizable structures. However, further regular polymerization was observed only for 2 , and its ladder-type PDA structure was supported by absorption bands in the near-IR region and ${ }^{13} \mathrm{C}-\mathrm{NMR}$ spectra. Thus, the introduction of urethane groups in side chains is quite effective for regular polymerization in the solid state. Unfortunately, the thin film formability of the monomers in this study was not sufficient to evaluate the NLO properties, and it will be interesting to improve the molecular structure for NLO study.

\section{ACKNOWLEDGEMENTS}

We thank Prof Akihiko Kanazawa and his laboratory members for their cooperation with powder XRD measurements. This study was partially supported by a Grant-in-Aid for Scientific Research on Priority Areas (no. 446) from the Ministry of Education, Culture, Sports, Science and Technology.

1 Wegner, G. Topochemische Reakionen von Monomeren mit Konjugierten Dreifachbindungen I. Mit.: Polymerisation von Derivaten des 2.4-Hexadiin-1.6-diols im Kristallinen Zustand. Z. Naturforsch. 24b, 824-832 (1969).

2 Enckelman, V. in Structural Aspects of the Topochemical Polymerization of Diacetylenes, Polydiacetylenes (ed. Cantow, H.- J.) vol. 63, 91-136 (Adv. Polym. Sci., Springer-Verlag, Berlin, 1984).

3 Nakanishi, H., Matsuda, H. \& Kato, M. Preparation of a variety of polymeric conductors from diacetylenes. Mol. Cryst. Liq. Cryst. 105, 77-88 (1984).

4 Takami, K., Kuwahara, Y., Ishii, T., Akai-Kasaya, M., Saito, A. \& Aono, M. Significant increase in conductivity of polydiacetylene thin film induced by iodine doping. Surf. Sci. 591, L273-L279 (2005).

5 Chance, R. R., Patel, G. N. \& Witt, J. D. Thermal effects on the optical properties of single crystals and solution-cast films of urethane substituted polydiacetylenes. $J$. Chem. Phys. 71, 206-211 (1979).

6 Tachibana, H., Kumai, R., Hosaka, N. \& Tokura, Y. Crystal structures, polymerization, and thermochromic phase changes in urethane-substituted diacetylenes crystals with varying alkyl chain lengths. Chem. Mater. 13, 155-158 (2001).

7 Kim, J.- M., Lee, J. -S., Choi, H., Sohn, D. \& Ahn, D. J. Rational design and in-situ FTIR analyses of colorimetrically reversibe polydiacetylene supramolecules. Macromolecules 38, 9366-9376 (2005).

8 Sauteret, C., Hermann, J. -P., Frey, R., Pradère, F., Ducuing, J., Baughman, R. H. \& Chance, R. R. Optical nonlinearities in one-dimensional-conjugated polymer crystals. Phys. Rev. Lett. 36, 956-959 (1976).

9 Carter, G. M., Hryniewicz, J. V., Thakur, M. K., Chen, Y. J. \& Meyler, S. E. Nonlinear optical processes in a polydiacetylene measured with femtosecond duration laserpulses. Appl. Phys. Lett. 49, 998-1000 (1986).

10 Bakarezos, M., Camacho, M. A., Blewett, I. J., Kar, A. K., Wherrett, B. S., Matsuda, H., Fukuda, T., Yamada, S., Rangel-Rojo, R., Katagi, H., Kasai, H., Okada, S. \& Nakanishi, $H$. Ultrafast nonlinear refraction in integrated fabry-perot etalon containing polydiacetylene. Electron. Lett. 35, 1078-1079 (1999).

11 Matsuzawa, H., Okada, S., Sarkar, A., Matsuda, H. \& Nakanishi, H. Synthesis of ladder polymers containing polydiacetylene backbones connected with methylene chains and their optical properties. J. Polym. Sci. Pt. A: Polym. Chem. 37, 3537-3548 (1999).

12 Matsuo, H., Okada, S., Nakanishi, H., Matsuda, H. \& Takaragi, S. Solid-state polymerization of monomers possessing two diphenylbutadiyne moieties with amido groups to form ladder polymers. Polym. J. 34, 825-834 (2002).

13 Sarkar, A., Okada, S., Matsuzawa, H., Matsuda, H. \& Nakanishi, H. Novel polydiacetylenes for optical materials: beyond the conventional polydiacetylenes. J. Mater. Chem. 10, 819-828 (2000).

14 Nakanishi, H., Matsuda, H., Okada, S. \& Kato, M. Evaluation of nonlinear optical susceptibility of polydiacetylenes by third harmonic generation. Polym. Adv. Technol. 1, 75-79 (1990).

15 Okada, S., Ohsugi, M., Masaki, A., Matsuda, H., Takaragi, S. \& Nakanishi, H. Preparation and nonlinear optical property of polydiacetylenes from unsymmetrical diphenylbutadiynes with trifluoromethyl substituents. Mol. Cryst. Liq. Cryst. 183, 81-90 (1990).

16 Sarkar, A., Okada, S., Nakanishi, H. \& Matsuda, H. Polydiacetylenes from asymmetrically substituted diacetylenes containing heteroaryl side groups for third-order nonlinear optical properties. Macromolecules 31, 9174-9180 (1998).

17 Matsuzawa, H., Okada, S., Sarkar, A., Matsuda, H. \& Nakanishi, H. Synthesis of polydiacetylenes from novel monomers having two diacetylene units linked by an arylene group. Polym. J. 33, 182-189 (2001).

18 Mizukoshi, K., Okada, S., Kimura, T., Shimada, S. \& Matsuda, H. Synthesis and solidstate polymerization of triyne and enediyne derivatives with similar $\pi$-conjugated structures. Bull. Chem. Soc. Jpn. 81, 1028-1037 (2008).

19 Okada, S., Hayamizu, K., Matsuda, H., Masaki, A. \& Nakanishi, H. Structures of the polymers obtained by the solid-state polymerization of diyne, triyne, and tetrayne with long-alkyl substituents. Bull. Chem. Soc. Jpn. 64, 857-863 (1991).

20 Okada, S., Hayamizu, K., Matsuda, H., Masaki, A., Minami, N. \& Nakanishi, H. Solidstate polymerization of 15,17,19,21,23,25-tetracontahexayne. Macromolecules 27, 6259-6266 (1994).

21 Matsuzawa, H., Okada, S., Matsuda, H. \& Nakanishi, H. Synthesis and optical properties of polydiacetylenes from dodecahexayne derivatives. Proc. SPIE 2851, 14-25 (1996). 
22 Okada, S., Nakanishi, H., Matsuzawa, H., Katagi, H., Oshikiri, T., Kasai, H., Sarkar, A., Oikawa, H., Rangel-Rojo, R., Fukuda, T. \& Matsuda, H. Improved third-order nonlinear optical properties of polydiacetylene derivatives. Proc. SPIE 3796, 76-87 (1999).

23 Ikoma, T., Okada, S., Nakanishi, H., Akiyama, K., Tero-Kubota, S., Möbius, K. \& Weber, S. Spin soliton in a $\pi$-conjugated ladder polydiacetylene. Phys. Rev. B 66, 014423 (2002).

24 Yang, S. \& Kertesz, M. Theoretical design of low band gap conjugated polymers through ladders with acetylenic crosspieces. Macromolecules 40, 6740-6747 (2007).

25 Katayama, K. Master Thesis (Tohoku University, 2001).

26 Okada, S., Matsuda, H., Otsuka, M., Kikuchi, N., Hayamizu, K., Nakanishi, H. \& Kato, M. Synthesis and solid-state polymerization of $\omega$-(1,3-Butadiynyl) substituted 1 alkanol and alkanoic acid. Bull. Chem. Soc. Jpn. 67, 455-461 (1994).

27 Okada, S., Matsuda, H., Otsuka, M., Nakanishi, H. \& Kato, M. Synthesis and solid-state polymerization of ù-(4-Aryl-1,3-butadiynyl) substituted 1-alkanol and alkanoic acid. Bull. Chem. Soc. Jpn. 67, 483-489 (1994).

28 Gross, H., Sixl, H., Kröhnke, C. \& Enkelmann, V. Structural changes and intermediate radical states in the photopolymerization of a diacetylene single crystal. Chem. Phys. 45, 15-26 (1980)
29 Patel, G. N., Duesler, E. N., Curtin, D. Y. \& Paul, I. C. Solid state phase transformation of a diacetylene by solvation. crystal structure of a moderately reactive monomer form. J. Am. Chem. Soc. 102, 461-466 (1980).

30 Brouty, C., Spinat, P. \& Whuler, A. Structural determination of the 2,4-hexadiyne-1,6diyl Bis[(para-chlorophenyl)carbamate] monomer, $\mathrm{C}_{20} \mathrm{H}_{14} \mathrm{Cl}_{2} \mathrm{~N}_{2} \mathrm{O}_{4}$ at $163 \mathrm{~K}$. Acta Crystallogr. C 39, 594-597 (1983).

31 Fisher, D. A., Ando, D. J., Batchelder, D. N. \& Hursthouse, M. B. Structure of 3,5Octadiyne-1,8-diol at 120 K. Acta Crystallogr. B 34, 3799-3801 (1978).

32 Enckelmann, V. Solid-state reactivity of triacetylenes. Chem. Mater. 6, 1337-1340 (1994).

33 Shinbo, H., Feeder, N., Okada, S., Matsuda, H., Nakanishi, F. \& Nakanishi, H. Solidstate polymerizability of esters and amides of alkadiynedioic acid. Mol. Cryst. Liq. Cryst. 315, 41-46 (1998).

34 Hanson, A. W. Two crystal structures of 2,4-Hexadiynylene dibenzoate. Acta Crystallogr. B 31, 831-834 (1975).

35 Barrow, M. J., Lough, A. J. \& Milburn, G. H. W. Structure of hexa-2,4-diyne-1,6-diyl Bis(4-methylbenzonate). Acta Crystallogr. C 45, 1595-1598 (1989). 